\title{
VALOR DA SOJA E SEU IMPACTO NA MOVIMENTAÇÃO PORTUÁRIA: APLICAÇÃO PARA O CASO DA SOJA NO PORTO DE RIO GRANDE
}

\author{
R.O, Santana ${ }^{1, *} ;$ R.F. Peres ${ }^{1}$; M.V. Nascimento ${ }^{1}$ \\ 1 Faculdade de Tecnologia de São José dos Campos - Professor Jessen Vidal \\ Av. Cesare Mansueto Giulio Lattes, 1350 - Eugênio de Melo, São José dos Campos/SP, \\ CEP.: 12247-014, Brasil. \\ Telefone: (12) 3905-2423 \\ *rudney.santana@fatec.sp.gov.br
}

\begin{abstract}
RESUMO: O setor do agronegócio contribuiu com 23,5\% do PIB do Brasil em 2017, e tem forte participação na balança comercial. O complexo soja foi o principal setor exportador, com cerca de $40 \%$ do total da receita do agronegócio, tendo os portos como elo principal da cadeia logística. Dentre os portos brasileiros, o porto de Rio Grande se destaca na movimentação de commodities, sendo $40 \%$ das mercadorias movimentadas grãos, óleo ou farelo de soja. Com base na participação da soja no total movimentado no Porto do Rio Grande, este artigo tem como objetivo analisar os efeitos da cotação internacional da soja na movimentação de cargas do porto, para isto foi elaborada uma análise estatística com modelo de regressão multivariada utilizando dados do período de 2009 até 2016, que apontou uma variação de $0,13 \%$ na movimentação média do porto a cada $1 \%$ de variação na cotação da soja.
\end{abstract}

PALAVRAS-CHAVE: soja; movimentação; cotação; regressão multivariada.

ABSTRACT: The agribusiness sector contributed 23.5\% of Brazil's GDP in 2017, and has a strong participation in the trade balance. The soybean complex was the main export sector, with about $40 \%$ of total agribusiness revenue, with ports as the main link in the logistics chain. Among the Brazilian ports, the port of Rio Grande stands out in the movement of commodities, being $40 \%$ of the goods moved grain, oil or soybean meal. Based on the participation of soybean in the total movement of the port of Rio Grande, this article aims to analyze the effects of the international price of soybean on the movement of cargo in the port, for this was elaborated a statistical analysis with multivariate regression model using data from the period from 2009 to 2016 , indicating a variation of $0.13 \%$ in the average movement of the port to each $1 \%$ variation in the price of soybean.

KEYWORDS: soy; movement; price; multivariate regression.

\section{INTRODUÇÃO}

O aumento da demanda mundial por alimentos abriu espaço para o Brasil competir globalmente no mercado das exportações de commodities, isso permitiu que a soja ganhasse escala, elevando o país ao patamar de potência agrícola (ABAG, 2015).

O complexo soja, composto pela soja em grãos e seus derivados como óleo e farelo de soja, foi o principal produto exportado em 2016, representando $13,72 \%$ de toda a exportação brasileira, ou seja, US\$ 25,42 bilhões, ficando à frente de produtos importantes como minérios, petróleo e 
combustíveis (CONAB, 2017). Os preços no mercado nacional de soja em grãos são afetados por vários fatores, tais como fretes, impostos, despesas administrativas e quebras técnicas que interferem diretamente nos preços internos. No entanto, os fatores que mais afetam os preços nacionais são as variações do dólar e, principalmente, os preços internacionais (CONAB, 2017).

Porém, segundo Ministério do Desenvolvimento, Indústria e Comércio Exterior (MDIC), as exportações de 2014 foram estimadas em US\$ 225,10 bilhões; em 2015, US\$ 191,13 bilhões; e, em 2016, US\$ 185,23 bilhões, sendo, portanto, o segundo ano consecutivo em que as exportações brasileiras têm diminuído.

\subsection{Problema em Estudo}

De acordo com Stülp e Plá (1992), um dos segmentos que mais interfere na eficiência dos diversos setores da economia de um país é o segmento de transporte. No cenário brasileiro o modal rodoviário é predominante para o transporte internacional de cargas agrícolas, sendo, por vezes a única alternativa para a movimentação deste tipo de produto (OJIMA, 2004).

Neste cenário o transporte de cargas agrícolas brasileiro se desenvolve tendo boa parte de seu foco em commodity, que se caracteriza como sendo um produto primário de importância global com baixíssimo grau de diferenciação (OLIVEIRA, 2012). Nas últimas décadas o complexo da soja obteve grande desenvolvimento, tornando-se hoje o principal ativo agrícola que movimenta a economia em todos os setores, com grande influência em sua complexa cadeia de atuação (ABAG, 2015).

O setor agrícola tem grande importância na economia brasileira. Em 2017, toda a cadeia de agronegócio no país gerou 23\% do PIB nacional (CNA, 2017), e segundo o Departamento de Agricultura dos Estados Unidos (USDA), o Brasil é o maior exportador de soja do mundo, e ocupa a segunda posição como produtor dessa commodity ficando atrás somente dos EUA (USDA, 2017)

Apesar de tanta importância o IMEA (2015), afirma que os gargalos, os custos elevados de transporte e a falta de infraestrutura dos portos, acabam refletindo negativamente sobre os preços recebidos pelos produtores, assim reduzindo a competitividade da soja brasileira. Conforme ressalta Alderton (2005), os portos são considerados o principal elo da cadeia logística no transporte de mercadorias, atendendo a necessidade da movimentação de diversos tipos de cargas, além de serem agentes estratégicos do crescimento econômico mundial.

Nesse caso, é relevante citar a participação do Porto do Rio Grande no escoamento da soja nacional, sendo utilizado como principal corredor de exportação e importação do extremo sul, é considerado o segundo mais importante porto do país para o desenvolvimento do comércio internacional brasileiro (CUNHA, 2016). Conforme dados divulgados pela CONAB, o porto do Rio Grande recebe $80 \%$ de toda a produção de soja do estado do Rio Grande do Sul, sendo responsável por $90 \%$ das exportações do estado, além de ser utilizado para exportar boa parte da produção de soja do estado de Mato Grosso, o maior produtor do Brasil.

\subsection{Objetivo do Trabalho}

O objetivo deste trabalho é avaliar os efeitos da cotação internacional da soja na movimentação de cargas do porto do Rio Grande.

Para a consecução deste objetivo foram estabelecidos os objetivos específicos:

- Pesquisa sobre os temas: sistemas portuários e movimentação de granéis;

- Levantamento de dados entre os anos de 2009 e 2016;

- Desenvolver análise estatística dos dados levantados com modelo de regressão multivariada.

\subsection{Proposta Metodológica}

Para atender os objetivos deste trabalho, a metodologia de pesquisa utilizada foi estruturada como demonstra a Figura 1: 


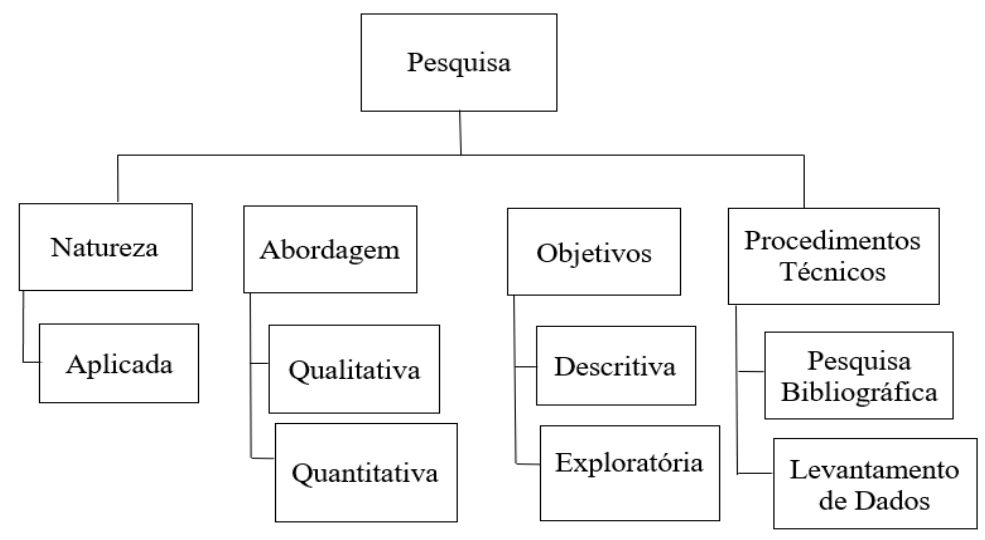

Figura 1. Proposta Metodológica.

\section{SISTEMA PORTUÁRIO NACIONAL}

Segundo a Secretaria Nacional de Portos, o Brasil possui uma costa de 8,5 mil quilômetros navegáveis, um setor portuário que movimenta anualmente cerca de 1,086 bilhão de toneladas das mais diversas mercadorias e responde por mais de $90 \%$ das exportações do país.

Existem hoje trinta e quatro portos públicos marítimos sob a gestão da SEP/PR. Dezoito deles são administrados diretamente pelas Companhias Docas, que são sociedades de economia mista, que têm como acionista majoritário o Governo Federal (SEP, 2018). A Figura 2 abaixo mostra, em termos de volumes transportados, os maiores terminais e portos organizados do Brasil.

\begin{tabular}{|l|c|c|}
\hline \multicolumn{1}{|c|}{ Porto / TUP } & 2017 & UF \\
\hline TUP PONTA DA MADEIRA & 169.785 .841 & MA \\
\hline TUP TUBARÃO & 109.253 .722 & ES \\
\hline PORTO DE SANTOS & 106.543 .173 & SP \\
\hline PORTO DE ITAGUAÍ & 52.938 .062 & R」 \\
\hline TUP SÃO SEBASTIÃO (ALMIRANTE BARROSO) & 49.334 .763 & SP \\
\hline PORTO DE PARANAGUÁ & 45.559 .090 & PR \\
\hline TUP ILHA GUAÍBA - TIG & 43.549 .107 & $\mathrm{RJ}$ \\
\hline TUP ANGRA DOS REIS & 42.313 .886 & $\mathrm{RJ}$ \\
\hline PORTO DO RIO GRANDE & 26.171 .271 & $\mathrm{RS}$ \\
\hline PORTO DO SUAPE & 23.631 .472 & $\mathrm{PE}$ \\
\hline
\end{tabular}

Figura 2. Toneladas por Terminas/Portos.

Em 2017, conforme divulgado pela ANTAQ, o volume de cargas transportadas nos terminais e portos organizados do Brasil obteve um crescimento 8,3\% comparado com o ano de 2016. Os terminais de uso privado movimentaram 721,6 milhões de toneladas, o que gerou um crescimento de 9,3\% em relação ao ano anterior, quando foram movimentados 660 milhões de toneladas. Já os portos públicos foram responsáveis pela movimentação de 364,5 milhões de toneladas, um aumento de 6,3\% sobre 2016 onde 342,8 milhões de toneladas foram movimentadas.

Importante observar que na figura onde é demostrado os 10 maiores portos por volume movimentado, 5 são terminais de uso privativo e somente 5 são portos organizados. No ano de 2017 os terminais privados (TUPS) movimentaram $66,4 \%$ de toda a movimentação em toneladas do país, os portos públicos movimentaram 33,6\% (ANTAQ, 2017). 


\subsection{Legislação do sistema portuário}

Os portos são uma parte importante da cadeia logística e sua eficiência contribui para a competitividade do país em mercados internacionais (CRAVEIRO, 2015). No caso do Brasil, a demanda por serviços portuários de maior qualidade aumentou nos últimos anos, com um crescimento econômico voltado para o comercio exterior (WANKE, 2013). No entanto, segundo Craveiro (2015), os estudos relacionados ao caso brasileiro indicam a presença de terminais portuários ineficientes no país.

O Brasil iniciou a sua participação no comércio internacional por meio da abertura dos portos durante o reinado de D. João VI em 1808, período em que eram constituídas as bases do atual sistema portuário brasileiro (NETO et al, 2009). A Lei das Concessões, foi criada em 1869 e levou à aceleração desse processo por meio da autorização do financiamento privado. Futuramente, em 1975, foi criada a Empresa Brasileira de Portos S.A. (Portobrás), que passou a exercer a função de operador portuário e autoridade portuária nacional, administrando os principais portos comerciais do país (CRAVEIRO, 2015).

Segundo Fontes (2006), com o Estado no controle do sistema portuário, preocupações com custos, produtividade e qualidade deixaram de existir. Consequentemente, o sistema portuário brasileiro ficou conhecido, até então, por problemas de pouco desenvolvimento tecnológico, baixa produtividade, baixo investimento, excesso de burocracia (COUTINHO et al, 2013). Nas últimas décadas, no entanto, ocorreram importantes modificações no setor portuário brasileiro (CRAVEIRO, 2015). Em 1993, foi editada a Lei de Modernização dos Portos, a Lei no 8.630/1993, com atuação sobre o regime jurídico da exploração dos portos organizados e das instalações portuárias e conferindo outras resoluções (FARRANHA et al, 2014).

A Lei de Modernização dos Portos teve como objetivo alcançar eficiência e competitividade no setor portuário, concedendo autonomia para os portos, incentivando a concorrência a nível regional por meio da isenção de tarifas, redefinindo o papel dos setores público e privado na construção e operação da infraestrutura portuária do país (MARCHETTI e PASTORI, 2009).

Por um lado, o setor privado passaria a ser o responsável pela instalação, recuperação e conservação dos equipamentos necessários para a operação dos terminais, por meio de concessões e arrendamentos e por intermédio dos operadores portuários. Por outro lado, o setor público continuaria responsável pela infraestrutura e pelas funções de fiscalização e promotoria do porto, passando o controle dos portos para as administrações portuárias estaduais e para as Companhias Docas (CRAVEIRO, 2015).

Desse modo, o Estado deixou de exercer o papel de prestador de serviços, apesar de continuar sendo o detentor da infraestrutura (FONTES, 2006). No novo modelo, as funções de planejamento e regulação do sistema continuam sob responsabilidade do Ministério dos Transportes, cuja função era a formulação de políticas dentro do seu âmbito de atuação. A Agência Nacional de Transportes Aquaviários (ANTAQ) e a Secretaria Nacional de Portos (SEP), estavam ainda com atividades até então, relacionadas à implementação de políticas (CRAVEIRO, 2015).

Ainda segundo Craveiro (2015), a Lei no 8.630 instituiu o financiamento por parte do Banco Nacional de Desenvolvimento Econômico (BNDES) para os investimentos em portos e terminais portuários e para a compra de equipamentos para o setor privado por meio da linha de crédito para o Financiamento de Máquinas e Equipamentos (FINAME).

\subsection{Nova lei dos portos}

Apesar dos avanços obtidos com o aumento da participação privada na indústria portuária, ainda existiam restrições à instalação de terminais privados, como, por exemplo, o estabelecimento do manuseio de carga própria como prioridade (CRAVEIRO, 2015). Com isso, em 07 de dezembro de 2012, ocorreu uma nova reforma da legislação portuária brasileira por meio da Medida Provisória no 
595, transformada na Lei Ordinária 12.815/2013 (Nova Lei dos Portos), aumentando a segurança jurídica para a participação do setor privado na operação dos terminais portuários (SILVA e OLIVEIRA, 2013).

A Nova Lei dos Portos tem como objetivo a modernização dos portos brasileiros e a eficiência nas operações logísticas realizadas por estes terminais (SIMÃO et al, 2017). Com a edição desta nova lei, buscou-se dar maior agilidade às transações e modernizar o setor. Os arrendamentos portuários passaram a ser regulados de forma semelhante a uma concessão de serviço público, destacando-se parâmetros de desempenho e a regulação tarifária (FARRANHA et al, 2014).

Ainda segundo Farranha et al. (2014), a nova legislação traz importantes inovações, como o critério de julgamento nas licitações de arrendamentos, a não obrigatoriedade de pagamento de valor de outorga para a assunção das áreas, a maior facilidade para o estabelecimento de portos privados e modificações na caracterização de terminais de uso privativo.

A Lei no 12.815/2013 também redefiniu as competências das instituições envolvidas no setor portuário. Uma maior centralização das atividades nos entes federais - Secretaria de Portos (SEP) e Agência Nacional de Transportes Aquaviários (ANTAQ) - permite uma maior coordenação das atividades referentes às novas licitações e auxilia na padronização do sistema de arrendamentos entre os portos brasileiros. A criação da Nova Lei dos Portos fez com que se estendesse a abertura à participação privada no setor portuário, na tentativa de se eliminar as restrições remanescentes à constituição de terminais de uso privativo (COUTINHO et al, 2013).

\subsection{Logística de distribuição da soja}

O desenvolvimento da soja no Brasil iniciou-se quando os primeiros materiais genéticos foram introduzidos no país e testados no Estado da Bahia em 1882. Em 1900, a soja foi testada no Rio Grande do Sul, o mais setentrional dos estados brasileiros, onde as condições climáticas são similares às encontradas na região de origem (sul dos EUA) dos materiais avaliados (DALL'AGNOL et al, 2007).

Ainda segundo Dall'agnol et al (2007), foi a partir da década de 1970 que a cultura da soja obteve grande desenvolvimento no Brasil e se consolidou como a principal cultura do agronegócio nacional. Este crescimento se deu devido ao aumento da área cultivada e ao aumento da produtividade.

Atualmente a soja representa $49 \%$ da produção nacional de grãos, sendo extremamente relevante para a balança comercial brasileira (CONAB, 2017). O principal destino da soja brasileira e seus derivados é a exportação. O farelo de soja é ofertado aos mercados interno e externo é utilizado, principalmente, na elaboração de rações para alimentação animal e o óleo produzido atende à demanda interna e externa (DALL'AGNOL et al, 2007).

Os fatores que auxiliam para o Brasil se destacar em relação à produção de soja são definidos pela disponibilidade de terras férteis, o clima favorável, a mão de obra disponível e por dispor de área própria (ANTUNES et al, 2015).

Dentre as regiões produtoras de soja no Brasil destacam-se quatro regiões (EMBRAPA, 2018):

- Região tradicional, formada pelos estados do Rio Grande do Sul, Santa Catarina, Paraná e São Paulo;

- Região de expansão consolidada, que compreende os estados de Minas Gerais, Goiás, Mato Grosso, Mato Grosso do Sul e Distrito Federal;

- Região de expansão recente, que abrange Bahia, Piauí e Maranhão;

- Região de potencial para expansão, abrangendo Rondônia, sul do Amazonas, leste do Pará e Oeste de Tocantins e Maranhão.

O Brasil, embora tenha papel de destaque na produção e comercialização da soja, sendo o maior exportador de soja do mundo, enfrenta dificuldades para fazer o escoamento da produção, perdendo 
competitividade em relação aos custos logísticos, principalmente no que se refere a infraestrutura (CARMO et al, 2009). Martins et al (2005), afirma que o Brasil está diante de uma situação em que o limite para a expansão da produção agrícola atualmente é dado pela logística e não pela disponibilidade de terras aptas à produção da agropecuária.

De acordo com a Confederação Nacional do Transporte, no ano de 2017 , cerca de $61 \%$ do transporte de cargas no Brasil foi feito através do modal rodoviário, sendo ferroviário e hidroviário responsáveis por $20,7 \%$ e $13,6 \%$, respectivamente. Nota-se uma grande dependência do transporte rodoviário em relação às commodities agrícolas (REIS et al, 2008). A soja, por ser um produto com baixo valor agregado e transacionado em grandes volumes, necessita de um modal de transporte de grande capacidade e baixo custo unitário, mesmo que não sejam considerados outros atributos, como a frequência e o prazo de produção (MARTINS et al, 2005).

Um dos principais obstáculos que enfrenta o agronegócio e influencia diretamente na sua eficácia está relacionado ao custo, bem como à falta de competência dos órgãos públicos em relação à infraestrutura, gerando prejuízos e aumento no Custo Brasil, que está acima dos padrões internacionais (GUDOLLE, 2016). A infraestrutura no Brasil se desenvolveu com pouca intensidade, aos poucos as empresas estão focando no processo de integração das atividades logísticas. Esse cenário é fruto de uma política econômica que vem, ao longo de várias décadas, sendo adotada pelo governo federal. Sobretudo a logística de transporte vem sendo desenvolvida pelo governo sem a devida preocupação com custos, qualidade e produtividade (FREITAS, 2003).

Segundo Dall'agnol et al (2007), a maior parte da comercialização da soja dá-se através de empresas privadas transnacionais e nacionais. Com relação as agroindústrias, grande parte está localizada junto às principais zonas produtoras e o produto para processamento é adquirido diretamente do produtor. Os principais importadores de soja do Brasil nos últimos anos são: China, Espanha, Tailândia, Países Baixos, Irã e Paquistão. Os principais portos de escoamento da soja brasileira têm sido o porto de Santos (SP), Paranaguá (PR), Rio Grande (RS) e São Francisco do Sul (SC), que movimentam a soja procedente de Mato Grosso, Mato Grosso do Sul e Paraná (EMBRAPA, 2018).

\subsection{O valor da soja}

Por ser uma commodity, a soja é um produto de grande importância em todo o mundo, além de ter padrão e cotação internacional, podendo ser negociada nas bolsas de futuro de todo o mundo (OLIVEIRA, 2012). O preço da soja na região onde é produzida depende da cotação internacional, que é baseada na bolsa de Chicago (MACHADO, 2010). A bolsa de Mercadorias de Chicago (CBOT) é a principal referência para a formação dos preços internacionais da soja (IMEA, 2015). Conforme dito por Machado (2010), isso se deve ao fato de a mesma apresentar alta concentração de ofertantes e demandantes dos países que mais produzem ou importam soja em todo o mundo, além de ser a bolsa de valores mais antiga do mundo, fundada em 1848.

O preço da soja é calculado no ato da negociação com o vendedor, de acordo com as cotações de Chicago e a taxa de câmbio no momento da negociação, mas não necessariamente no momento da entrega e por outros fatores, como demanda interna para esmagamento (IMEA, 2015).

A negociação de contrato futuro é realizada com vencimentos nos meses de setembro, novembro, janeiro, março, maio, julho e agosto, onde cada contrato é referente a 5.000 bushels, que equivale a $136.000 \mathrm{~kg}$ de soja negociados em dólar por bushel. Os vencimentos nesses meses se tornam referência para a formação do preço da soja no comércio internacional (CEOLIN, 2012).

Segundo o IMEA (2015), o preço da soja a ser pago ao produtor envolve as seguintes variáveis:

- Cotação da soja na bolsa de Chicago;

- Prêmio praticado no dia da negociação;

- Custos portuários; 
- Custo com o frete rodoviário.

Conforme Machado (2010), prêmio de exportação é a diferença entre o valor da soja definido na Bolsa de Chicago e o preço do produto dentro do navio, no porto onde será feita a exportação, ou seja, o preço FOB (free on board) da soja. A negociação do prêmio envolve indústrias, empresas importadoras, tradings, cooperativas exportadoras de grãos e corretoras de prêmio (MORAES, 2002). O mesmo autor divide as variáveis que influenciam no prêmio em: movimentação física da soja, disponibilidade de produto na origem e de produtos substitutos e valor relativo para o importador.

Desta forma deve-se somar o preço da soja da CBOT com o prêmio no porto, o resultado deve ser reduzido pelo custo portuário. Logo após, deve-se multiplicar o valor obtido pelo dólar para converter as variáveis de dólar para reais e, em seguida, o resultado deve ser reduzido do frete rodoviário (IMEA, 2015).

\section{APRESENTAÇÃO DA BASE DE DADOS}

Para o desenvolvimento deste trabalho, foi construída uma série histórica com as variáveis: movimentação total, movimentação de cargas sólidas do porto do Rio Grande e cotação da saca da soja. Os dados foram coletados no período de 2009 até 2016 com frequência mensal.

A figura 3 abaixo demonstra a movimentação do porto do Rio Grande durante o período estudado:

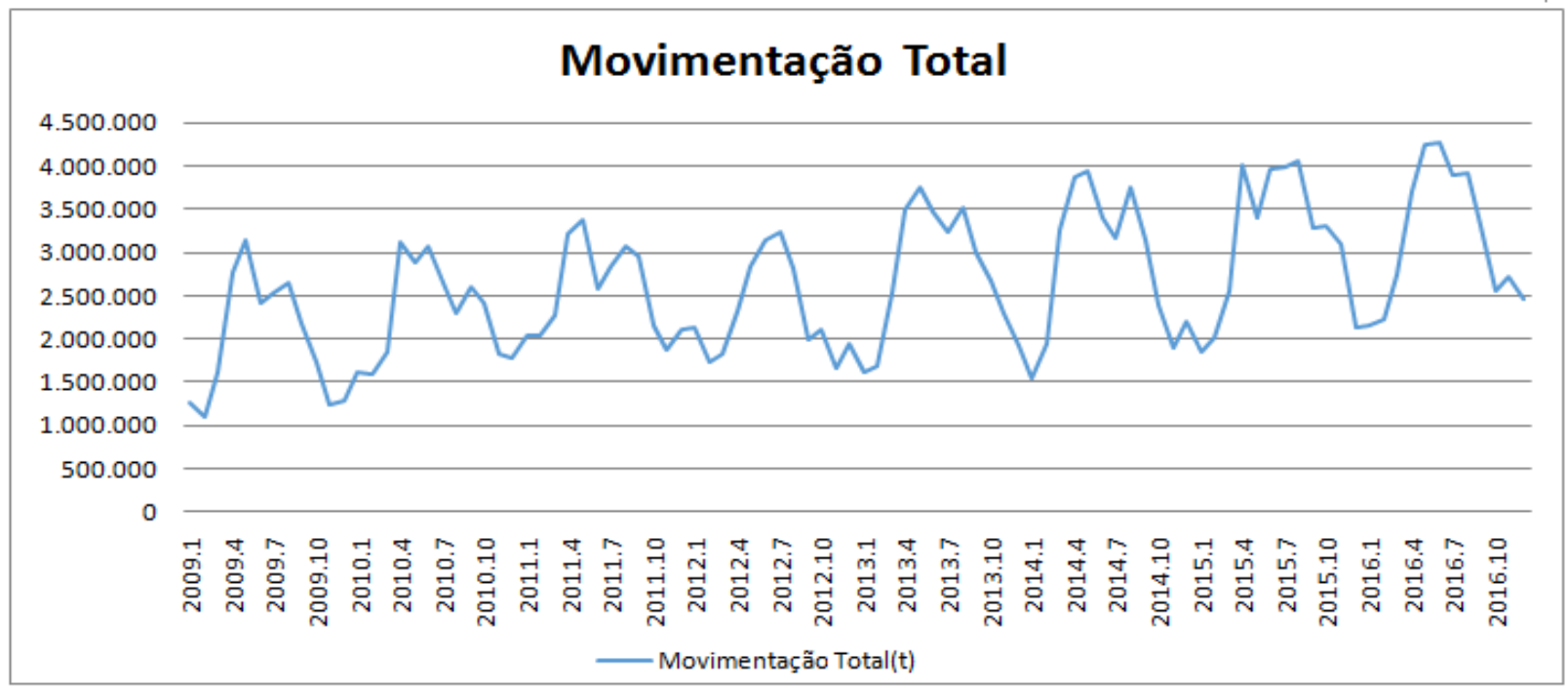

Figura 3. Movimentação do porto ao longo dos anos.

Observa - se que as movimentações do porto estão sob crescimento ano a ano, porém no ano de 2012, houve uma diminuição acentuada na movimentação de soja em relação a 2011, esta diminuição é atribuída à queda da safra 2011/2012 de soja no Rio Grande do Sul, provocada por uma forte estiagem em função do fenômeno La Niña. De acordo com o boletim anual da ANTAQ, o La Ninã provocou uma queda de $35 \%$ da produção de soja da região.

Importante ressaltar, que pelo seu papel no escoamento da soja no estado, o porto do Rio Grande possui uma movimentação de graneis sólidos muito alta, representado assim boa parte de sua movimentação portuária como visto na figura 4 abaixo: 


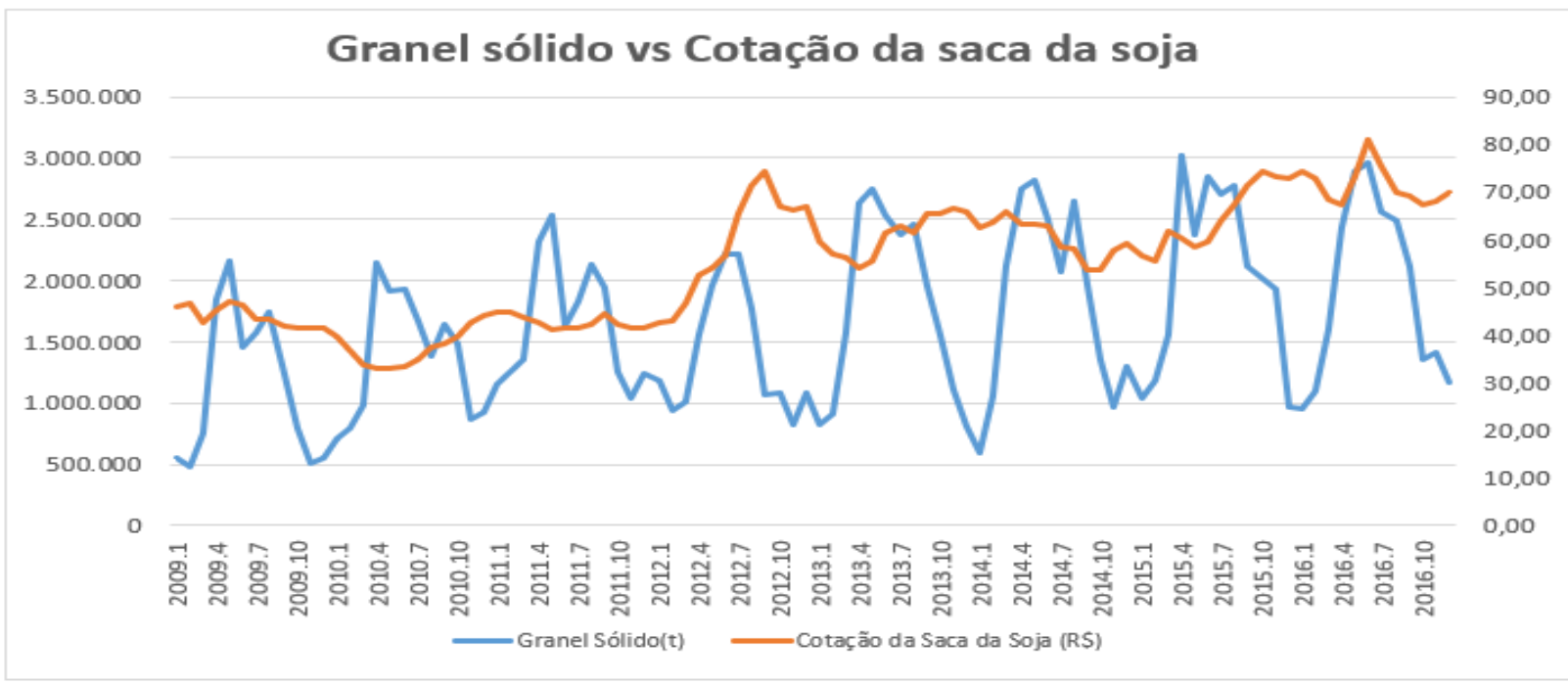

Figura 4. Movimentação de granel sólido e cotação da saca da soja.

\section{MODELAGEM ESTATÍSTICA E ANÁLISES}

De posse da série histórica elaborada, passou-se a análise dos dados e a construção do modelo de regressão proposto no trabalho. Antes da realização do modelo de regressão foi feita uma análise de correlação dos dados com o auxílio da ferramenta de análise de dados do Excel conforme visto na Figura 5:

\begin{tabular}{|lrrr|}
\cline { 2 - 5 } \multicolumn{1}{c|}{} & Ln mov. Total & Ln Granel & Ln Cotação \\
\hline Ln mov. Total & 1 & & \\
Ln Granel & 0,983798879 & 1 & 1 \\
Ln Cotação & 0,356440619 & 0,263740367 & 1 \\
\hline
\end{tabular}

Figura 5. Resultado da correlação entre as variáveis.

Analisando os resultados gerados na correlação, a variável granel sólido possui um grau de correlação de 0,98 que indica uma correlação muito forte, que pode ser explicada pela alta quantidade de soja que passa pelo porto. A variável cotação da saca de soja apresentam um grau de correlação fraco, que é resultado de sua grande oscilação. Segue abaixo o modelo de regressão multivariada demonstrado na Figura 6:

\begin{tabular}{|c|c|c|}
\hline \multicolumn{3}{|c|}{ RESUMO DOS RESULTADOS } \\
\hline \multicolumn{2}{|c|}{ Estatistica de regressão } & \\
\hline \multirow{3}{*}{$\begin{array}{l}\text { R-Quadrado } \\
\text { Observações }\end{array}$} & 0,977967043 & \\
\hline & 96 & \\
\hline & Coeficientes & valor-P \\
\hline Interseção & 3,666756992 & $7,24468 \mathrm{E}-23$ \\
\hline In Granel & 0,651581777 & $4,15758 \mathrm{E}-76$ \\
\hline Ln Cotação & 0,137276683 & 3,4173E-09 \\
\hline
\end{tabular}

Figura 6. Resultado do modelo de regressão. 
Para a realização deste estudo, foram criadas variáveis logarítmicas para se estabelecer um modelo de regressão Logarítmico-linear ou modelo Log-log. Esse tipo de modelo permite avaliar o efeito de uma variação percentual de X em Y.

Nota-se que o P-valor de todas as variáveis estudadas permite a aceitação de todos os coeficientes com $99 \%$ de confiança. Os coeficientes representam o efeito da variável independente e da constante na variável explicada. O modelo apresentou um alto R2, o valor obtido de 0.97 demonstra que $97 \%$ da movimentação total do porto pode ser explicada pelas variáveis introduzidas no modelo: Granel sólido e cotação da saca da soja.

A constante da regressão múltipla é de 3,66675, o coeficiente da variável independente granel sólido é de 0,6515 , e da cotação da saca da soja é de 0,13721 ou seja, se houver o aumento de $1 \%$ na variação percentual da cotação da soja, causará uma variação média mensal na movimentação do porto de $0,13 \%$ e para cada variação de $1 \%$ na movimentação de granel sólido, causará uma variação na movimentação do porto de $0,65 \%$. O resultado demonstra incialmente que a cotação traz vantagens benéficas para o porto aumentando sua movimentação, conforme dito pela ABAG (2015), os preços da soja beneficiam os agricultores apresentando lucratividade e incentivando aumento na área plantada para próximas safras, consequentemente aumentando a movimentação dos portos.

\section{CONSIDERAÇÔES FINAIS}

Este trabalho teve por objetivo analisar os efeitos da cotação da soja na movimentação total do porto do Rio Grande, tendo em vista que a soja é a principal commodity do agronegócio brasileiro e seu complexo (grãos, óleo e farelo de soja) responde por $40 \%$ das cargas movimentadas pelo porto do Rio Grande. A série histórica, que foi elaborada para a realização do modelo de regressão, demonstrou uma grande sazonalidade na movimentação do porto que é um reflexo dos períodos de safra e entressafra da soja. Observou -se também uma variação na cotação da soja, que apresenta ao longo dos anos uma tendência de aumento nos valores pagos por saca.

Com o auxílio da ferramenta de análise do Excel, foi possível demonstrar que os valores encontrados com a modelagem são positivos, já que demonstram que a cotação da soja tem impacto positivo e significante sobre a movimentação total do porto. Como futuras pesquisas sugerimos um modelo de regressão entre a cotação da soja e o volume de soja exportado nacionalmente.

\section{REFERÊNCIAS}

ABAG. O Futuro da Soja Nacional - Impactos socioeconômicos da ferrugem asiática na cadeia da soja nos próximos dez anos. Disponível em http://www.abag.com.br/media/images/0futuro-da-soja-nacional---ieag---abag.pdf. Acesso em: 05/05/2018.

ALDERTON, P. Port Management and Operations. London/Hong Kong: LLP, 2005.

ANTAQ - Estatístico aquaviário. Anuário 2017. Disponível em http://web.antaq.gov.br/Anuario/. Acesso em: 18/05/2018.

ANTAQ - Boletim Portuário correspondente ao quarto trimestre de movimentação de carga. 2012. Disponível em hhttp://portal.antaq.gov.br/wp-content/uploads/2017/03/BoletimPortu\%C3\%A1rio-correspondente-ao-quarto-trimestre-de-movimenta\%C3\%A7\%C3\%A3ode-carga.-.pdf. Acesso em: 10/07/2018. 
ANTUNES, A.C.L.; NAZARÈ, T. B.; BORGES, C. S.; LIPPI, R. A logística de transporte da soja no Brasil: comparação entre modais e a atual situação do país. IX Encontro de engenharia de produção agroindustrial. 2015.

CARMO, B.B.T.; PONTES, H. L. J.; PORTO, A. J. V. Problemas logísticos na exportação brasileira da soja em grão. Revista Eletrônica Sistemas \& Gestão. Vol. 4, n. 2, p. 155-181, Niterói, mai.-ago. 2009.

CEOLIN, M. Comercialização da soja: Uma análise das principais alternativas disponíveis ao produtor. Especialização em Agronegócio - Universidade Federal do Paraná, 2012.

CNA. Confederação da Agricultura e Pecuária do Brasil. Boletim Estatístico - 2017. Disponível em: http://www.cnabrasil.org.br/central-comunicacao/boletins. Acesso em: 13/07/2018.

CNT. Confederação Nacional do Transporte - Boletim Estatístico 2017. Disponível em http://cms.cnt.org.br/Imagens\%20CNT/BOLETIM\%20ESTAT\%C3\%8DSTICO/BOLETIM \%20ESTAT\%C3\%8DSTICO\%202017/Boletim\%20Estat\%C3\%ADstico\%20-\%2002\%20$\% 202017 . p d f$. Acesso em: 03/08/2018.

CONAB. Perspectivas para a agropecuária - Safra 2017/2018. Companhia Nacional de Abastecimento. v1. Brasília: Conab, 2017.

COUTINHO, P. C.; BRITTO, P. A. P.; LUCAS, V. M.; LUSTOSA, P. R.; ALBUQUERQUE.; CARVALHO, A. T.; FONSECA, A.; OLIVEIRA, A. R. Modelos de estrutura do setor portuário para análise da concorrência. Economics and Politics Working Paper. 24/2013, 2013.

CRAVEIRO, G. L. Os Granéis sólidos no Brasil: uma aplicação da Análise Envoltória de Dados (DEA). 70f. Dissertação (Mestrado em Ciências Econômicas) - UnB - Universidade de Brasília, 2015.

CUNHA, C.N. Reforma da logística do porto do Rio Grande e desenvolvimento urbano. Revista Grifos. Vol. 25, n. 40, p. 183-207. 2016.

DALL'AGNOL, A.; ROESSING, A.C.; LAZAROTTO, J.J.; HIRAKURI, M. H.; OLIVEIRA, A. B.; O complexo agroindustrial da soja brasileira. Embrapa Soja. Circular técnica. Vol.43, Londrina, 2007.

EMBRAPA. Empresa brasileira de pesquisa agropecuária. - Arvore de conhecimento da soja. Disponível em http://www.agencia.cnptia.embrapa.br/gestor/soja/arvore/CONTAG01_15_271020069131.ht ml. Acesso em: 17/07/2018.

FARRANHA, A. C.; FREZZA, C. S.; BARBOSA, F. O. Nova Lei dos Portos: Desafios Jurídicos e Perspectivas de Investimentos. Revista Direito GV. v. 11, p. 089-116. Jun. 2014.

FONTES, O. Avaliação da eficiência portuária através de uma modelagem DEA. Dissertação de Mestrado, Universidade Federal Fluminense. 2006. 
FREITAS, L. A. Importância da eficiência logística para o posicionamento competitivo das empresas no mercado internacional. RAU - Revista de Administração. Unime. 2003.

GUDOLLE, M. F. Os custos logísticos da soja em grãos: Estudo de Caso em uma Empresa Cerealista no município de Cruz Altas-RS. 64f. Dissertação (Mestrado em Desenvolvimento Rural) - Unicruz - Universidade de Cruz Alta, 2016.

IMEA. Entendo o Mercado da Soja. Workshop Jornalismo Agropecuário. Jun. 2015.

MACHADO. L. O. Fatores de formação do preço da soja em Goiás. 2010. Disponível em https://docplayer.com.br/8434690-Fatores-de-formacao-do-preco-da-soja-em-goias.html.

Acesso em: 03/08/2018.

MARCHETTI, D.; PASTORI, A. Dimensionamento do potencial de investimentos para o setor portuário. BNDES, 2009.

MARTINS, R. S.; D. Rebechi; C. A. Prati e H. Conte. Decisões estratégicas na logística do agronegócio: compensação de custos transporte-armazenagem para a soja no estado do Paraná. Revista de Administração Contemporânea, v. 9, n. 1, p. 53-78. 2005.

MDIC. Ministério da Industria, Comercio exterior e Serviços. Disponível em: http://www.mdic.gov.br/index.php/comercio-exterior/estatisticas-de-comercio-exterior/serieshistoricas. Acesso em: 05/06/2018.

MORAES, M. Prêmio de exportação da soja brasileira. 90p. Tese de Mestrado em Ciências, Área de Concentração: Economia Aplicada. Escola Superior de Agricultura Luiz de Queiroz, Universidade de São Paulo, Piracicaba. 2002.

NETO, C. A. S. C.; FILHO, B. P.; ROMMINGER, A. E.; FERREIRA, I. M.; VASCONCELOS, L. F. Gargalos e demandas da infraestrutura portuária e os investimentos do PAC: Mapeamento IPEA de obras portuárias. Texto para discussão, IPEA, 2009.

OJIMA, A. L. R. O. Análise da movimentação logística e competitividade da soja brasileira: uma aplicação de um modelo de equilíbrio espacial de programação quadrática. 2004. 79 p. Tese (Mestrado) - Faculdade de Engenharia Elétrica e de Computação, Universidade Estadual de Campinas, São Paulo.

OLIVEIRA, Cassio Antunes. Infraestrutura de transportes: Análise dos principais modais no estado de São Paulo. Revista. Formação Online, São Paulo, v. 1, n. 49, p. 124-150, jan./jun., 2012.

REIS, J. D.; DAMACENO, L. B.; CRUZ, J. C.; ZILL, J. B. Custo Ótimo de transporte rodoviário das principais regiões produtoras de soja aos principais portos do Brasil. XLVI Congresso da Brasileira de Economia, Administração e Sociologia Rural. Piracicaba. 2008. 
SEP. Secretaria Nacional de Portos. Sistema portuário nacional. Disponível em: http://www.portosdobrasil.gov.br/assuntos-1/sistema-portuario-nacional. Acesso em: $18 / 04 / 2018$.

SILVA, C.; OLIVEIRA, D. Nota descritiva. Medida Provisória n. 595, de 2012. Consultoria Legislativa. Câmara dos Deputados. Brasília. 2013.

SIMÃO, F. S.; SOUZA, R. S.; SILVA, S. W.; JUNIOR, P. S. P. Os impactos da nova lei dos portos na eficiência logística do porto de Santos. $69^{\circ}$ Reunião Anual da SBPC. Belo Horizonte. 2017.

STÜLP, V. J; PLÁ, J.A. Estudo do setor agroindustrial da soja. 1992. 168p.- Universidade Federal do Rio Grande do Sul, Porto Alegre.

USDA. United States Department of Agriculture - Oilseeds: word Market and trade. Foreign Agricultural Service. Jun. 2017.

WANKE, Petter. Physical infrastructure and shipment consolidation efficiency drivers in Brazilian ports: A two-stage network-DEA approach. Revista Transport Policy, v. 29, n. C, p. 145-153, 2013. 